\title{
Informática educacional na educação básica e inclusiva
}

\author{
Jacqueline Leire Roepke* \\ Valdecir Reginaldo de Oliveira** \\ Marcelo Martins ${ }^{* * *}$
}

\begin{abstract}
Resumo
Entre percalços que escolas enfrentam diante da realidade do uso das tecnologias da informação e comunicação, coexistem diferentes opiniões quanto ao uso delas no ambiente escolar inclusivo. O objetivo desse artigo foi levantar dados, reflexões, sugestões e posicionamentos presentes em pesquisas que versam sobre a informática educacional na educação básica e inclusiva. Trata-se de uma pesquisa bibliográfica que investigou artigos científicos disponíveis na base de dados da Biblioteca Virtual em Saúde - Psicologia Brasil. A pesquisa apresenta alguns aspectos que podem estar por trás da negação ou da aceitação do uso das tecnologias digitais na esfera educacional. A maioria dos artigos encontrados defende que as tecnologias são muito contributivas no processo de ensino e aprendizagem, e que a relutância ao uso delas, ou mesmo as dificuldades de usá-las por parte das crianças, não deve eximir os professores de incentivarem essas crianças a irem se aproximando das tecnologias.
\end{abstract}

Palavras-chave: educação, inclusão, tecnologias.

\section{Educational informatics in basic and inclusive education}

\begin{abstract}
Among the obstacles that schools face regarding the use of information and communications technologies, different opinions coexist on their use in an inclusive school environment. The objective of this article was to collect data, reflections, suggestions and assessments present in researches on the topic of educational computing in basic and inclusive education. This is a bibliographical research that investigated scientific articles available in a database. The research presents some aspects that may be behind the denial or acceptance of the use of digital technologies in inclusive school environments. Most of the encountered articles defend technology as contributing in the teaching and learning processes, and that reluctance to use them, or even difficulties in using them by children, should not keep teachers from encouraging students to approach these technologies.
\end{abstract}

Keywords: education, inclusion, technologies.

\section{Introdução}

Este trabalho tem como objetivo analisar dados obtidos por pesquisas que versam sobre a informática educacional na educação básica e inclusiva, difundidas em uma determinada base de dados. Como objetivos específicos, procurou-se identificar

\footnotetext{
* Psicóloga. Mestre em Educação. Especialista em Psicopedagogia. Docente do curso de Educação Especial da UNIASSELVI. E-mail: jacleire@ gmail.com.

** Pedagogo. Especialista em Informática Educacional. Tutor interno do curso de Pedagogia da UNIASSELVI. E-mail: guyodaister@ hotmail.com.

*** Professor. Doutor em Teologia. Docente dos cursos de Teologia, Pedagogia e Letras-Libras da UNIASSELVI. E-mail: marcelo.martins@ uniasselvi.com.br.
} 
posicionamentos dos autores dos artigos científicos sobre a temática em questão; levantar as reflexões expressas pelos autores; e relatar as sugestões presentes nas pesquisas.

Trata-se de uma pesquisa bibliográfica (GIL, 2011), que foi conduzida por meio de um levantamento de artigos científicos na base de dados da Biblioteca Virtual em Saúde - Psicologia Brasil. As expressões que foram utilizadas para a busca nos indexadores da base de dados foram: informática, educação, inclusão, informática educacional, educação básica e educação inclusiva; foram feitas diferentes associações entre as expressões selecionadas. Primeiramente, foram localizados artigos que discorrem sobre a temática dessa pesquisa de modos distintos. Depois de selecionados, os artigos foram respectivamente lidos e analisados, a fim de obter subsídios para compor o presente trabalho.

No estudo da temática pesquisada, algumas ações pedagógicas revelam o posicionamento de que crianças com necessidades educacionais especiais não precisam aprender/usar tecnologias da informação e da comunicação com tanta intensidade quanto as demais, já que o principal papel da escola é a socialização e não a aprendizagem em si. Por outro lado, impera o discurso de que as tecnologias digitais podem facilitar o processo de ensino e aprendizagem - sobretudo para crianças com deficiência e/ou necessidades educacionais especiais. Simultaneamente, encontram-se professores que demonstram indiferença ou resistência ao uso das tecnologias digitais e aqueles que deixam as crianças com deficiência realizando atividades desvinculadas dos letramentos digitais, enquanto o restante da classe participa das aulas com informática educacional.

Para Lucena (2016), assim como as tecnologias de informação e comunicação conectadas em rede em distintos setores sociais caracterizou o século XX, o emprego das tecnologias móveis e redes sociodigitais está caracterizando o século XXI de modo ainda mais intensificado. As tecnologias têm sido utilizadas sobretudo pelas pessoas jovens e, parte delas, já nem consegue mais imaginar processos de aprendizagem que não perpassados por essas tecnologias.

Além dos desafios que a utilização das tecnologias impõe aos professores, é válido lembrar que, dia após dia, crianças com deficiência e/ou com necessidades educacionais especiais estão estudando em escolas regulares (DINIZ; BARBOSA; SANTOS, 2009). Existem muitas polêmicas que envolvem a inclusão de crianças e adolescentes com deficiência nas redes de ensinos regulares, públicas e privadas. Ainda é possível ouvir 
professores dizendo que não foram preparados para atender um público tão diversificado de alunos, isto é, que apresentam características e necessidades tão diferentes entre si. Nesse contexto, faz-se necessário enfatizar que adolescentes se sentem pertencentes a um grupo, acolhidos e úteis entre seus pares quando incluídos de forma humana. Destaca-se que eles não devem ser considerados vítimas da sociedade, mas sim cobrados dentro das suas potencialidades (LIBORIO, et al., 2015). Nesse sentido, muitas escolas brasileiras têm demonstrado dedicação na criação de um ambiente para acolher estudantes com necessidades educacionais especiais, sem negligenciar ou apressar o aprendizado deles (SANTAROSA; CONFORTO, 2015).

Além da acessibilidade arquitetônica dos espaços escolares, e das adequações ou adaptações curriculares, existem outras temáticas que têm feito parte dos discursos das pessoas que trabalham com a educação. Santos e Martins (2015), por exemplo, dão ênfase às práticas pedagógicas voltadas à inclusão escolar e relacionadas, também, com a educação especial, sobretudo com estudantes que apresentam deficiência intelectual. Conforme Santos e Martins (2015, p. 406), "[...] há na escola a disponibilidade de material pedagógico e tecnológico, que, caso fosse mais utilizado, poderia contribuir significativamente para a aprendizagem de todos os alunos". De acordo com Duarte et at., as práticas pedagógicas inclusivas podem ser incrementadas com o uso de tecnologias de informação e comunicação e de diferentes metodologias, além das tecnologias assistivas (DUARTE et al., 2013). Estes mesmos autores se referem ao ensino e aprendizagem de pessoas com surdez ao longo da história e mencionam barreiras de comunicação, bem como o uso de língua de sinais e o método oral.

Herrera, Fernandez e Seguel (2018) explicitam a Política Pública definida no Chile acerca da utilização dessas tecnologias para fins educacionais. Esses pesquisadores investigaram a percepção de professores do Chile sobre a incorporação das tecnologias de informação e comunicação como práticas de ensino. Também abordaram as competências que essas tecnologias requerem dos professores e alguns aspectos normativos.

Aqui no Brasil também há documentos que tratam do uso das tecnologias de informação e comunicação no seio escolar. A BNCC - Base Nacional Comum Curricular é um deles. Nesse documento a expressão "tecnologias digitais" aparece setenta e seis 
vezes como, por exemplo, no excerto a seguir que faz alusão às competências gerais da educação básica:

\footnotetext{
Compreender, utilizar e criar tecnologias digitais de informação e comunicação de forma crítica, significativa, reflexiva e ética nas diversas práticas sociais (incluindo as escolares) para se comunicar, acessar e disseminar informações, produzir conhecimentos, resolver problemas e exercer protagonismo e autoria na vida pessoal e coletiva (BRASIL, 2017, p. 9 , grifo nosso).
}

Liborio et al. (2015) defendem que celulares e computadores, por exemplo, podem contribuir sobremaneira tanto na facilitação quanto na estimulação da comunicação entre os estudantes, e destes com outros interlocutores. Isso ilustra a importância do uso das tecnologias de informação e comunicação nas escolas inclusivas.

Entretanto, indivíduos com alguma deficiência ou não, nem sempre conseguem por si sós desenvolverem ações que venham a contemplar as suas habilidades tecnológicas. Portanto, é essencial que os governos criem recursos didáticos para que avancem nesta direção (SANTAROSA; CONFORTO, 2015). Além do mais, é basilar que as escolas contem com professores de informática educacional que possam acompanhar e assessorar os estudantes no espaço educacional.

\section{Informática educacional na educação básica e inclusiva: Dados}

Ao perceberem que os alunos adolescentes se recobram diante das situações de proteção advindas do convívio em grupo Liborio, et al., (2015) desenvolveram uma pesquisa. Fizeram parte dela 16 adolescentes com idade entre 14 e 17 anos, que demonstravam dificuldades em meio à sociedade da qual faziam parte. Destes, quatro adolescentes com deficiência física ou auditiva que estudam em escolas regulares participaram desta pesquisa. Tudo foi minuciosamente filmado e fotografado para compor uma estrutura adequada aos estudos, tendo a Teoria Fundamentada nos Dados (TFD) como elemento norteador.

De maneira geral, Liborio et al., (2015) concluíram que, a despeito do prisma que se pode colocar, vários aspectos devem ser considerados:

a) a inter-relação entre colegas e professores, em especial o professor intérprete (no caso de Libras); 
b) como as tecnologias da informação e comunicação podem facilitar a transmissão de mensagens com interlocutores sem deficiência e;

c) as formas de enfrentamento da dor e das limitações físicas com vistas ao bemestar a médio prazo. Muitas vezes as estratégias de enfrentamento da dor adotadas por estudantes com deficiência física envolvem profissionais da saúde, tais como fisioterapeutas, médicos etc. Os familiares e amigos também costumam auxiliar as crianças e adolescentes com deficiência a apresentarem atitudes ativas e persistentes. Contudo, a escola deve ser um lugar de inclusão e amparo para adolescentes com deficiência, bem como um ambiente apropriado para o convívio na sociedade. Na escola, esses estudantes deveriam encontrar condições favoráveis à aprendizagem, ao aperfeiçoamento. Deveriam também encontrar condições favoráveis para terem contato com a Libras e intérpretes e apoio da sala de recursos multifuncionais (SRM) de atendimento educacional especializado (AEE). Deveriam ainda ter acesso a metodologias de ensino diversificadas, adaptação nas avaliações e estímulo para que superem momentos de desinteresse e desmotivação.

Estudantes com deficiência podem ser mais suscetíveis a terem dificuldades no aprendizado. Por exemplo: a pessoa surda ou com deficiência auditiva pode se deparar com dificuldades para se comunicar, ler e escrever. Ademais, pode enfrentar situações que obstaculizam o seu aprendizado na escola. É natural que adolescentes com estas características procurem aperfeiçoar-se buscando uma relação recíproca para o seu sucesso, que pode acontecer na relação com colegas, familiares, nas SRM, e com os profissionais do AEE (LIBORIO et al., 2015). Apesar disso, as possibilidades de desenvolvimento na escola para as crianças com deficiência não deveriam se restringir à SRM e ao AEE.

A busca por auxílio e para formação de parcerias de estudo com colegas também pode acontecer de forma autônoma e espontânea e ser mediada pelas ferramentas das tecnologias de informação e comunicação. Santarosa e Conforto (2015) expressam que instrumentos tecnológicos - como tablets, celulares, computadores e outros - facilitam o processo de ensino e aprendizagem de pessoas com deficiência, tornando-as pertencentes ao grupo e interligando as relações com maior praticidade. Vieira e Pacheco (2004) esclarecem, por sua vez, que a limitação sensorial obrigatoriamente traz à tona a necessidade de estudos que envolvam o uso das tecnologias da informação e comunicação 
no meio escolar. Diante disso, fizeram uma pesquisa com enfoque no aluno surdo. As dificuldades que os surdos enfrentam no uso da internet foram focalizadas. A integração de estudantes surdos também foi analisada em articulação com os aspectos ergonômicos cognitivos.

Os surdos não têm sido o único público alvo de pesquisas nesse sentido. Santarosa e Conforto (2015) investigaram o uso de dispositivos das tecnologias de informação e comunicação por estudantes com TEA ${ }^{1}$. Buscaram estudar os limites e avanços que podem ser alcançados no âmbito da escola. Foram adotadas metodologias qualitativas na perspectiva exploratória, explicativa e cognitiva, tendo relação com temas sóciohistóricos, trazendo duas importantes questões: 1) Equipamentos portáteis apresentam facilidade de manuseio às pessoas com TEA; 2) O que se originou frente ao uso destes equipamentos para que acontecesse um benéfico avanço para adolescentes com TEA?

Três alunos foram os sujeitos da pesquisa de Santarosa e Conforto (2015). Essas pesquisadoras focalizaram o contato desses estudantes dos anos iniciais da Educação Básica com a interface gráfica e com ferramentas portáteis de informação e comunicação. Foram identificadas tanto potencialidades quanto fragilidades. Foi verificado pouco interesse pela utilização de laptop's educativos. As pesquisadoras supõem que essa indiferença frente ao equipamento esteja relacionada com as características de crianças/adolescentes com TEA. Dentre elas, destacam-se: limitadas habilidades no uso da tecnologia; dificuldades com aspectos abstratos; modos diferenciados de comunicação. Sendo assim, pode ser que os estudantes não tenham compreendido plenamente o que se pretendia. Além do mais, as funcionalidades do equipamento se mostraram muito complexas para eles.

Santarosa e Conforto (2015) explicam que o tablet se mostrou uma tecnologia de fácil manuseio, sendo similar ao celular, tecnologia tão utilizada por tantas pessoas na atualidade. A portabilidade impera entre as comodidades características do tablet, ganhando destaque no uso por alunos com características relativas ao TDAH ${ }^{2}$. É válido lembrar que, por vezes, as crianças com TEA apresentam comportamentos similares àquelas com TDAH, o que pode inclusive gerar equívocos no processo diagnóstico.

\footnotetext{
${ }^{1}$ Transtorno do Espectro Autista.

2 Transtorno de Déficit de atenção e Hiperatividade.
} 
O oeste de Minhas Gerais foi palco para a pesquisa feita por Cavalcante (2017). Ela foi conduzida por itens quanti-qualitativos em uma escola pública. Dados foram colhidos através de uma sequência de perguntas, de um AVA - Ambiente Virtual de Aprendizagem - e de anotações diárias. Foram verificados dados quantitativos por meio de estatística de descrição. Já a análise de conteúdo foi utilizada para analisar os dados qualitativos. No decorrer da verificação do uso do AVA foram percebidas situações frágeis no uso decorrente da inclusão em meios digitais, sendo verificados diferentes modos de utilização desta tecnologia. Mesmo tendo uma linguagem simples e exposta a erros, ocorreram relatos de cyberbullying no início desta interação. Fatos como, por exemplo, o difícil acesso às tecnologias pela comunidade envolvida foram notados, sendo constatadas dificuldades no acesso digital destes adolescentes no cenário brasileiro.

No cenário atual, os estudantes que apresentam certa dificuldade - tanto físicas, como de acesso geográfico - são inseridos na escola regular, participando dos processos de alfabetização. Algumas formações continuadas têm sido disponibilizadas aos professores. Pode-se verificar no meio educacional demandas tecnológicas que estão chegando para viabilizar o acesso dos alunos com alguma deficiência. As tecnologias de informação e comunicação têm sido utilizadas com o uso de novas formas de linguagem e de comportamento. Porém, ainda existem poucas pesquisas sobre elas (VIEIRA; PACHECO, 2004).

O Brasil dispõe de leis específicas sobre pessoas com deficiência como, por exemplo, a Política Nacional para a Integração da Pessoa Portadora de Deficiência ${ }^{3}$ Decreto Lei n. ${ }^{\circ} 3.298$, que regulamenta a Lei n. ${ }^{\circ}$ 7.853, de dezembro de 1989, bem como políticas de amparo às pessoas com deficiência (VIEIRA; PACHECO, 2004).

Tendo em vista a nossa legislação e a política voltada para a Educação Especial sob o prisma da Educação no Brasil, o estudante com deficiência tem prejuízos no que concerne sua matrícula e efetiva participação nas classes ditas inclusivas. Exemplificando, os horários reduzidos oferecidos por determinadas escolas aos estudantes com TEA, bem como a preponderância de atividades voltadas ao brincar social, no espaço educativo, para tais crianças (SANTAROSA; CONFORTO, 2015). É bem verdade que o brincar social contribui para o desenvolvimento de várias habilidades articuladas ao ato de se comunicar e de aprender, se mostrando eficaz também junto ao

\footnotetext{
${ }^{3}$ Atualmente, a expressão mais usada e correta é "Pessoa com Deficiência - PcD”.
} 
desenvolvimento psicomotor. Contudo, se faz necessário recordar que uma das características do TEA é justamente a preferência por atividades e brincadeiras individuais, sem a presença de outras pessoas/crianças (SANTAROSA; CONFORTO, 2015).

A interação entre pessoas demanda melindrosas integrações da linguagem verbal, não verbal, de componentes cognitivos e emocionais. Pessoas com TEA geralmente apresentam dificuldades em um ou mais desses quesitos. Sendo assim, alunos com TEA necessitam de estímulos compostos por diversificadas estratégias voltadas ao desenvolvimento social, ou seja, de terem maior contato com os colegas. Esse estímulo não pode ficar restrito ao brincar social. As escolas têm papel decisivo para que a interação entre os pares seja representativa e de qualidade. Se o brincar social não é suficiente, que outras estratégias podem ser exploradas com essas crianças? (SANTAROSA; CONFORTO, 2015).

O fato é que muitas pessoas continuam acreditando que o principal papel da escola é propiciar às crianças um tempo e espaço de socialização. Talvez por isso ainda existem escolas e professores que não se mostram implicados com o processo de ensino e aprendizagem das crianças com deficiência (SANTAROSA; CONFORTO, 2015). Para eles, possivelmente a chance de estar e/ou circular em meio às outras crianças já é suficiente para tais estudantes. Será que a utilização das estratégias pedagógicas voltadas aos alunos com TEA, que são incrementadas com o uso de vídeos e músicas disponíveis na internet, não podem ser úteis para a socialização desses estudantes? "A interface tecnológica passou a operar como recurso educacional para minimizar o comportamento que fugia do padrão desejado para o perfil de um aluno matriculado em uma escola regular" (SANTAROSA; CONFORTO, 2015, p. 358).

Para Vieira e Pacheco (2004), as ferramentas de informação e comunicação colaboram no desenvolvimento cognitivo. Por isso, evidenciaram a cognição, em sua pesquisa, em conjunto com as facilitações possibilitadas pelo uso das novas tecnologias da informação e comunicação destinadas aos indivíduos com deficiências sensoriais.

É indiscutível que as novas tecnologias tendem a favorecer e estimular os processos de ensino e aprendizagem de pessoas com deficiência ou não. Javaroni e Zampieri (2015) explicam que a utilização de tecnologias de informação e comunicação pode favorecer tais processos, ainda que existam alguns impasses em torno do manuseio 
das tecnologias nos ambientes escolares. Essas pesquisadoras difundem as vantagens do uso das tecnologias de informação e comunicação por parte de professores da Educação Básica, mais especificamente, nas aulas de matemática. A familiaridade com as tecnologias da informação e comunicação sãos importantes para o desenvolvimento do sujeito com deficiência.

Javaroni e Zampieri (2015) focalizaram seus estudos sobre o ensino de matemática, Cruz (2018, p. 1), atenta para as potencialidades e limitações da implantação de tecnologias da informação e comunicação na formação transdisciplinar - abrangendo professores de diferentes disciplinas. Por exemplo, no tocante às competências específicas de história para o ensino fundamental, a BNCC faz as seguintes indicações: "Produzir, avaliar e utilizar tecnologias digitais de informação e comunicação de modo crítico, ético e responsável, compreendendo seus significados para os diferentes grupos ou estratos sociais" (BRASIL, 2017, p. 402, grifo nosso).

Scheid e Reis (2016), por sua vez, colocaram o enfoque sobre a articulação entre tecnologias de informação e comunicação em aulas de ciências naturais, voltadas ao desenvolvimento do cidadão em distintas dimensões como, por exemplo, a cidadania. No que respeita às competências específicas de ciências da natureza para o ensino fundamental, a BNCC propõe o seguinte: "Utilizar diferentes linguagens e tecnologias digitais de informação e comunicação para se comunicar, acessar e disseminar informações, produzir conhecimentos e resolver problemas das Ciências da Natureza de forma crítica, significativa, reflexiva e ética" (BRASIL, 2017, p. 324, grifo nosso).

A pesquisa de Santos (2019) realça o uso das tecnologias de informação e comunicação no ensino de língua portuguesa. A aplicação das tecnologias de informação e comunicação na disciplina de língua portuguesa deve contemplar a criticidade e a motivação para o aluno descobrir novas informações enraizadas no que se está estudando. Tendo em vista as competências específicas de linguagens para o ensino fundamental, a BNCC faz as seguintes recomendações:

Compreender e utilizar tecnologias digitais de informação e comunicação de forma crítica, significativa, reflexiva e ética nas diversas práticas sociais (incluindo as escolares), para se comunicar por meio das diferentes linguagens e mídias, produzir conhecimentos, resolver problemas e desenvolver projetos autorais e coletivos (BRASIL, 2017, p. 65, grifo nosso). 
De acordo com Cruz (2018, p. 1), uma das limitações advém de parte dos estudantes que "[...] não descartaram a possibilidade de se manter um espaço e um tempo específicos para a aprendizagem sobre tecnologias". Portanto, alguns alunos parecem reivindicar momentos destinados exclusivamente para a construção de conhecimentos acerca das tecnologias de informação e comunicação como, por exemplo, estratégias para manejo dos computadores. Em contrapartida, parece que cada vez menos têm sido ofertados cursos de informática básica tanto nas grades curriculares da rede de educação básica quanto nos cursos oferecidos por instituições que não vinculadas diretamente com escolas da educação básica. Cruz (2018, p. 15) ainda enfatiza que “[...] o próprio modelo curricular de matriz disciplinar constitui um paradigma difícil de quebrar".

\section{Algumas reflexões e apontamentos}

Santarosa e Conforto (2015) instigam algumas reflexões que são elencadas neste momento: Será que as escolas que ainda estão alinhadas à lógica da exclusão não se limitam a distrair as crianças com necessidades educacionais especiais, enquanto disponibilizam as tecnologias móveis e acessíveis aos demais alunos? Será que numa aula de informática educacional todas as crianças têm possibilidades de utilizar as ferramentas de informação e comunicação? Ou será que parte delas precisa se contentar com desenhos livres no papel, manipulação de massinha de modelar, enquanto a maior parte da turma vai se aproximando das práticas de letramentos digitais? Será que alguns alunos são deixados parados diante dos monitores nos laboratórios de informática porque professores julgam que eles não têm condições de aprender a utilizá-los?

Essa situação se mostra controversa. Os alunos que mais poderiam se beneficiar das tecnologias, por conta de suas características, são justamente aqueles que são menos encorajados a utilizá-las. Para uns, o laptop educacional pode ser útil, possibilizando que a mediação tecnológica se processe tanto dentro quanto fora da escola. Para outros, esse benefício pode ser alcançado com o ipad. Mas, até que ponto pode-se falar na inclusão de todos se as vantagens estão ao alcance das crianças que se encontram nas famílias ou nas instituições que desfrutam de melhores condições socioeconômicas? Se muitas crianças com deficiência têm dificuldades para chegar diariamente à escola, por conta da falta de condições mínimas para que se locomovam (meios de transporte e calçadas que não são 
compatíveis com cadeiras de roda, por exemplo), não seriam os equipamentos tecnológicos móveis uma grande possibilidade para que se viesse a conduzir parte de seu processo de aprendizagem no aconchego de seus lares?

Vieira e Pacheco (2004) mostram que tecnologia digital pode estar à disposição das pessoas oferecendo uma infinidade de benefícios. Dentre os benefícios, VilarinhoRezende et al. (2016) destacam o desenvolvimento da criatividade na esfera educacional. Essas pesquisadoras explicam que a variedade de tecnologias de informação e comunicação possibiliza que a criatividade seja estimulada e incrementada, internet e sistema digital ofertados a todos sem distinção de habilidades ou limitações sensoriais. Todavia, essas facilidades devem ser manipuladas no sentido de proporcionar às pessoas com deficiência condições para poder usufruir de tal modernidade, com acessibilidade e acompanhamento específico. Ou seja, é indispensável que as ferramentas sejam adaptadas, adequadas para que os estudantes com deficiência consigam manuseá-las apropriadamente. Uma sugestão é a criação de um portal específico e a atenção aos modos peculiares de operar as ferramentas e sites especializados (VIEIRA; PACHECO, 2004).

Santarosa e Conforto (2015) salvaguardam que a era digital pode beneficiar discentes e docentes, no entanto, as inovações nem sempre são acompanhadas de planejamentos adequados aos diferentes estilos de usuários. Não basta apenas a existência de equipamentos de última geração se na hora de serem manuseados nos processos de ensino aprendizagem as características peculiares das pessoas com deficiência não são respeitadas ou minimamente levadas em consideração. Portais especializados para os surdos, outros portais voltados para pessoas com deficiência visual, enfim, portais criados "sob medida" para cada grupo que integra o público com necessidades especiais podem ajudar muito no aprendizado deles. As limitações sensoriais podem ser superadas, total ou parcialmente, quando desenvolvidas ferramentas virtuais que facilitam o envolvimento do indivíduo com deficiência (VIEIRA; PACHECO, 2004).

A evolução no campo da educação especial precisa ter um aspecto dinâmico, com otimizações de técnicas específicas no intuito de melhorar sempre o processo de aprendizagem, juntamente com as novas tecnologias da informação e comunicação. Pessoas com deficiência sensorial serão mais envolvidas em situações de estudos acompanhadas da tecnologia (VIEIRA; PACHECO, 2004). 
Um fato curioso ocorreu no decorrer da pesquisa de Santarosa e Conforto (2015): um estudante com necessidades especiais não demonstrou afinidade com um tipo de equipamento (tablet). Diante disso, seus pais tiveram a ideia de comprar um dispositivo diferente (ipad), esperando que essa mudança tecnológica iria ser mais coerente com as necessidades e preferências de seu filho. A partir desse caso, questionamos se o acesso a diferentes equipamentos poderia contribuir para que estudantes identificassem com qual equipamento se sentem mais à vontade. É possível melhorar o processo de aprendizagem simplesmente trocando as tecnologias? (SANTAROSA; CONFORTO, 2015). Iniciativas de inclusão escolar e sociodigital não podem negligenciar, ignorar as especificidades do público-alvo da educação especial. Desde que os estudantes com necessidades educacionais especiais passaram a integrar as classes de escolas públicas brasileiras, não seria evidente que têm o direito ao manuseio de recursos diversos que prometem mediar o processo de ensino-aprendizagem? Todos os recursos tecnológicos ofertados aos alunos que não possuem deficiência devem estar também ao dispor dos alunos com necessidades especiais, apresentando, assim, características técnico-pedagógicas viáveis (SANTAROSA; CONFORTO, 2015).

Um outro exemplo: houve aversão ao computador por parte de algumas crianças. Supostamente esse desconforto se deu por conta da necessidade de manusear o mouse. Afinal, o tablet se mostrou uma ferramenta mais viável e intuitiva, já que pode ser tocado através do dedo em qualquer posição corporal (SANTAROSA; CONFORTO, 2015). O ideal seria que todos os estudantes, indiferentemente de terem deficiência ou não, fossem assistidos com práticas e ferramentas acessíveis, tanto virtuais como presenciais. Assim, poder-se-ia, de fato, falar em inclusão (SANTAROSA; CONFORTO, 2015).

Para que esse ideal seja um dia atingido não é suficiente que apenas os professores de informática educacional saibam utilizar os equipamentos tecnológicos. A nossa sociedade moderna convive quase que em sua totalidade com o mundo cibernético, e na escola não pode ser diferente. As tecnologias digitais devem dar suporte aos processos de ensino/aprendizagem nos mais variados contextos. Os recursos digitais podem minimizar distintas dificuldades, sejam elas oriundas de disciplinas que requerem mais mecanismos ou artifícios para que sejam compreendidas, sejam elas oriundas de características específicas dos estudantes como, por exemplo, necessidades educacionais especiais (SAITO; RIBEIRO, 2013). 
Diante do exposto, fica evidenciada a importância do uso das tecnologias da informação e comunicação nas escolas. A utilização de recursos digitais é muito conveniente, sendo uma ação facilitadora em meio aos diversos percalços que a didática pode encontrar no dia a dia no decorrer do processo de ensino e aprendizagem. Entretanto, Adams e Souza (2016) esclarecem que, apesar das inúmeras possibilidades disponibilizadas pelo uso das novas tecnologias, existem, concomitantemente, muitos desafios que perpassam essa situação. Por exemplo, a utilização de tantas ferramentas tecnológicas pode ser compatível com o processo de humanização que é tão essencial no processo educativo?

No que se refere aos desafios ao uso das tecnologias na educação, Saito e Ribeiro (2013) observam que muitos professores praticamente se recusam a utilizar a tecnologia ofertada, sendo por motivo de desconhecimento da ferramenta, por não acreditar nela, ou por ter resistências a ela. Assim, se torna premente a necessidade de que a formação de professores seja acrescida de estratégias que contribuam com o desenvolvimento de habilidades atinentes à informática.

Além das dificuldades experenciadas por professores nas tentativas de mediação do conhecimento por intermédio do uso de tecnologias de informação e comunicação, Schuhmacher, Alves Filho e Schuhmacher (2017) citam outros desafios que se descortinam para professores em seu contexto profissional. Desafios estes de ordem estrutural, epistemológica e didática. Um desafio de ordem estrutural apontado por Schuhmacher, Alves Filho e Schuhmacher (2017) é que não se encontram muitas iniciativas por parte de cursos e de instituições que estimulem a utilização de tecnologias de informação e comunicação enquanto recursos de mediação ou objeto de estudo entre os professores.

Conforme Schuhmacher, Alves Filho e Schuhmacher (2017), desafios de ordem epistemológica são aqueles concernentes à própria natureza do conhecimento em tecnologias de informação e comunicação. Por exemplo, as percepções, representações ou resistências de professores sobre o uso das tecnologias de informação e comunicação citadas por Saito e Ribeiro (2013),

pela observação dos aspectos já analisados, conclui-se que as TIC [tecnologias de informação e comunicação] na prática em sala de aula, para alguns professores, passam a ser bem mais do que um desafio: torna-se uma contradição respondida em muitas situações pela negação. A hipótese de que 
obstáculos epistemológicos estão presentes na construção do conhecimento em TIC pelos professores foi legitimada pelas interpretações propostas. Nelas, ficam evidentes (a) os equívocos e limitações na construção do conhecimento; (b) a apropriação do senso comum como verdadeiro; (c) a experiência sendo aceita como verdade sem que tenha havido a crítica e interpretação e (d) a busca apressada pela generalização levando a generalidades mal colocadas (SCHUHMACHER; ALVES FILHO; SCHUHMACHER, 2017, p. 575).

No que tange aos desafios de ordem didática, Schuhmacher, Alves Filho e Schuhmacher (2017) fazem menção às opções didáticas equivocadas quando o professor escolhe utilizar uma determinada tecnologia, motivado por suas experiências anteriores, mas que, na prática, se mostra como uma escolha inadequada, podendo gerar dispersão na turma para outras atividades.

O letramento digital deve fazer parte das formações continuadas dos professores não apenas para que eles entendam as funcionalidades do computador e seus similares, mas também para que compreendam que estas ferramentas podem auxiliá-los em situações complicadas durante a sua jornada pedagógica (SAITO; RIBEIRO, 2013). A renovação dos equipamentos, muitas vezes sucateados, faz parte da melhora do aprendizado, porém, a formação humana voltada para essa nova vivência também se faz necessária. Valores culturais, sociais, tecnológicos e econômicos inserem-se nesse quadro inovador com a chegada das tecnologias da informação e comunicação.

\section{Considerações Finais}

É inegável que as inovações tecnológicas chegaram para auxiliar, e na escola não poderia ser diferente. Assim como tudo - ou quase tudo - que se realiza atualmente depende da informática, os professores e alunos têm ao seu dispor o computador e outros dispositivos para instigar e incrementar o estudo. Conteúdos e disciplinas que comumente são perpassados por maiores dificuldades durante as aulas podem receber o auxílio dos recursos digitais, das tecnologias de informação e comunicação. Não são apenas os estudantes adultos que integram os cursos de educação a distância que podem ser favorecidos com o uso desses equipamentos.

No entanto, a criação de novos artefatos tecnológicos não ajuda por si só. É preciso que professores e estudantes sejam qualificados para interagirem e articularem novos usos para as tecnologias de informação e comunicação. Além do potencial para promover a 
interação, e consequentemente a aprendizagem cooperativa, isto pode oferecer diferentes suportes durante o processo de ensino/aprendizagem.

O professor bem preparado - tanto no lado técnico quanto pedagógico - vem a ser um grande aliado da sociedade para que a sua didática e trabalho façam ainda mais sentido na vida dos alunos. Até porque uma parte representativa desses estudantes tem rotineiramente manuseado celulares com internet, tendo acesso às mais variadas informações. Lembramos que o mundo moderno exige cada vez mais acesso às novas tecnologias.

$\mathrm{Na}$ escola, o uso do computador e de equipamentos similares é de relativa significância para o suporte das dificuldades encontradas no decorrer dos estudos, sendo uma ferramenta auxiliar no processo de ensino e aprendizagem. A Educação pode - e deve - ser agraciada com essas alternativas que são as tecnologias de informação e comunicação, perfazendo um novo paradigma para o olhar do aluno com que se motiva a descobrir novos horizontes sobre o que está estudando (SANTOS, 2019).

Alunos com necessidades educacionais especiais têm mais motivos ainda para que sejam factualmente estimulados a se inserirem nos letramentos digitais. Afinal, existem ferramentas tecnológicas e artefatos digitais que podem contribuir para que sejam suprimidas algumas de suas dificuldades.

A resistência de crianças que estão na educação básica perante os dispositivos tecnológicos, sistemas, software etc., ou as dificuldades de manuseá-las não devem justificar a redução na estimulação ao uso desses dispositivos. Pelo contrário, isto justifica que professores precisam construir conhecimentos com relação às tecnologias e desenvolver suas habilidades com elas.

\section{Referências}

ADAMS, Adair, SOUZA, Antônio Escandiel de. Linguagem e educação: reflexões acerca das novas tecnologias da comunicação. Linguagem em (Dis)curso. Tubarão, v. 16, n. 1, p. 169-179, abr. 2016. Disponível em: http://www.scielo.br/scielo.php?script=sci_artext\&pid=S1518-76322016000100169\&lng=en\&nm=iso. Acessoem: 18 jun. 2019.

BRASIL. Ministério da Educação. Base Nacional Comum Curricular. Brasília: MEC, 2017.

CAVALCANTE, Ricardo Bezerra et al. Inclusão digital e uso de tecnologias da informação: a saúde do adolescente em foco. Revista Perspectivas em Ciência da Informação. Belo Horizonte, v. 22, n. 4, p. 3-21, dez. 2017. Acesso em: 22 maio 2019. 
CRUZ, Elisabete. Representações de alunos sobre a integração curricular das TIC no ensino básico. Educação $e$ Pesquisa. São Paulo, v. 44, 2018. Disponível em: http//www.scielo.br/scielo.php?script=sci_arttext\&pid=S151797022018000100405\&lng=en\&nm=iso. Acessoem: 18jun. 2019.

DINIZ, Debora; BARBOSA, Lívia; SANTOS, Wederson Rufino dos. Deficiência, direitos humanos e justiça. Sur. Revista Internacional de Direitos Humanos. São Paulo, v. 6, n. 11, p. 6477, Dez 2009. Disponível em: http://www.scielo.br/scielo.php?script=sci_ arttext\&pid=S1806-64452009000200004\&lng=en\&nm=iso. Acesso em: 19 ago. 2018.

DUARTE, Soraya Bianca Reis et al. Aspectos históricos e socioculturais da população surda. História Ciência e Saúde - Manguinhos. Rio de Janeiro, v. 20, n. 4, out.dez. 2013. p. 1713 - 1734. Disponível em: http://www.scielo.br/scielo.php?script=sci_ arttext\&pid=S0104-59702013000401713\&lng=en\&nm=iso. Acesso em: 14 maio 2018.

GIL, Antonio Carlos. Métodos e técnicas de pesquisa social. $6^{\text {a }}$ ed. São Paulo: Atlas, 2011.

HERRERA, Marcelo Arancibia;FERNANDEZ, DanielaCosimo;SEGUEL, RobertoCasanova. Percepción de losprofesores sobre integración de TICenlasprácticas de enseñanza en relación a los marcos normativos para laprofesión docente em Chile. Ensaio: Avaliação e Políicas Públicas em Educação. Rio de Janeiro, v. 26, n. 98, p. 163-184, Mar. 2018. Disponível em: http://www.scielo.br/scielo.php?script=sci_arttext\&pid=S0104 40362018000100163\&lng=en\&nrm=iso. Acesso em: 18 jun. 2019.

JAVARONI,SueliLiberatti;ZAMPIERI,Maria Teresa. OUso das TIC nas Práticas dos ProfessoresdeMatemática da Rede Básica de Ensino: o projeto Mapeamento e seus desdobramentos. Bolema. Rio Claro, v. 29, n. 53, p. 9981022, dez. 2015. Disponível em: http://www.scielo.br/scielo.php?script=sci_anttext\&pid=S0103636X2015000300998\&lng=en\&nm=iso. Acessoem: 14 abr. 2019.

LIBORIO, Renata Maria Coimbra et al. Resiliência e Processos Protetivos de Adolescentes com Deficiência Física e Surdez Incluídos em Escolas Regulares. Revista Brasileira de Educação Especial. Marília, v. 21, n. 2 , p. 185-198, jun. 2015. Disponível em: http://www.scielo.br/scielo.php?script=sci_arttext\&pid=S141365382015000200185\&lng=pt\&nrm=iso. Acesso em: 22 maio 2019.

LUCENA, Simone. Culturas digitais e tecnologias móveis na educação. Educar em Revista. Curitiba, n. 59, p. 277-290, Mar. 2016. Disponível em: hittp:/www.scielo.br/scielo.php?script=sci_arttext\&pid=S0104 40602016000100277\&lng=en\&nrm=iso. Acesso em: 18 jun. 2019.

SAITO, Fabiano Santos; RIBEIRO, Patrícia Nora de Souza. (Multi)letramento(s) digital(is) e teoria do posicionamento: análise das práticas discursivas de professoras que se relacionaram com as tecnologias da informação e comunicação no ensino público. Revista Brasileira de Linguística Aplicada. Belo Horizonte, v. 13, n. 1, p. 37-66, mar. 2013. Disponível em: http://www.scielo.br/scielo.php?script=sci_arttext\&pid=S1984 $63982013000100003 \& \operatorname{lng}=$ pt\&nrm=is. Acesso em: 22 maio 2019.

SANTAROSA, Lucila Maria Costi; CONFORTO, Débora. Tecnologias móveis na inclusão escolar e digital de estudantes com Transtornos de Espectro Autista. Revista Brasileira de Educação Especial. Marilia, v. 21, n. 4, p. 349-366, dez. 2015. Disponível em: http:/www.scielo.br/scielo.php?script=sci_arttext\&pid=S141365382015000400349\&lng=pt\&nrm=iso. Acesso em: 22.05.2019. 
SANTOS, Teresa Cristina Coelho dos; MARTINS, Lúcia de Araújo Ramos. Práticas de Professores Frente ao Aluno com Deficiência Intelectual em Classe Regular. Revista brasileira em educação especial. Marilia, v. 21, n. 3, p. 395-408, set. 2015. Disponível em: http:/www. scielo.br/scielo.php?script=sci_arttext\&pid=S141365382015000300395\&lng=en\&nm=iso. Acesso em: 09 out. 2018.

SANTOS, Wéllia Pimentel. Tecnologias da informação e comunicação (Tics) e suas possibilidades de uso no ensino de língua portuguesa. Revista Polyphonía, v. 29, n. 2, 8 fev. 2019.

SCHEID, Neusa Maria John; REIS, Pedro Guilherme Rocha dos. As tecnologias da informação e da comunicação e a promoção da discussão e ação sociopolítica em aulas de ciências naturais em contexto português. Ciência e Educação. Bauru, v. 22, n. 1, p. 129-144, Mar. 2016. Disponível em: http:/www.scielo.br/scielo.php?script=sci_arttext\&pid=S1516-73132016000100129\&lng=en\&nrm=iso. Acesso em: 18 jun. 2019.

SCHUHMACHER, Vera Rejane Niedersberg; ALVES FLHO, José de Pinho; SCHUHMACHER, Elcio. As barreiras da prática docente no uso das tecnologias de informação e comunicação. Ciência e Educação. Bauru, v. 23, n. 3, p. 563-576, jul. 2017. Disponível em: http://www.scielo.br/scielo.php?script=sci_arttext\&pid=S1516$73132017000300563 \& \operatorname{lng}=$ en\&nm=iso. Acessoem: 18 jun. 2019.

VIEIRA, Eleonora Milano Falcão; PACHECO, Roberto Carlos dos Santos. O enfoque cognitivo e o uso das tecnologias de informação em situação de limitação sensorial. Cademos EBAPE.BR. Rio de Janeiro, v. 2, n. 2 , p. 01-10, jul. 2004. Disponível em: http://www.scielo.br/scielo.php?script=sci_arttext\&pid=S167939512004000200006\&lng=pt\&nrm=iso. Acesso em: 22 maio 2019.

VILARINHO-REZENDE, Daniela et al. Relação entre Tecnologias da Informação e Comunicação e Criatividade: Revisão da Literatura. Psicologia: Ciência e Profissão. Brasília, v. 36, n. 4, p. 877-892, dez. 2016. Disponível em: http://www.scielo.br/scielo.php?script=sci_arttext\&pid=S141498932016000400877\&lng=en\&nrm=iso. Acesso em: 18 jun. 2019. 